\title{
PENGARUH KEPEMIMPINAN, BUDAYA ORGANISASI, PENDAPATAN DI LUAR GAJI, DAN KEPUASAN KERJA TERHADAP MOTIVASI PEGAWAI BALAI METROLOGI JAWA TENGAH
}

\author{
Haryono dan Yayat Hidayat Amir \\ Badan Metrologi Wilayah Tegal dan Universitas Pancasakti Tegal \\ upstegal@gmail.com
}

\begin{abstract}
ABSTRAK
The aims of this research is to know the influence of independent variables (leadership, organization culture, and income out of salary) to dependent variables (job satisfaction and motivation). This research is doing using quantitative approach. Data of this research are response from 5 Likert Scale. On the income out of salary provide the opened questioners. Population on this research are employees on Meteorological Agency of Central Java consist of 6 Meteorological Agency that are Semarang area, Pati area, Tegal area, Banyumas area, Surakarta area, and Magelang area. Population consist of 160 employees on Meteorological Agency of Central Java take 114 sample by random technique and the proportion of 6 Meteorological Agency in Central Java area with refer to sampling technique of Slavin formula. This way done so that employees in Meteorological Agency in each territory can have the same chance to be a respondent. Therefore, all of proportional samples based on the number of employees in Meteorological Agency of each territory. Data analysis using regression technique to know the beta coefficient of regression as the method of calculating the analysis. Result of the research, 1) leadership doesn't significantly influence to motivation, and have indirect influence to motivation through job satisfaction; 2) organization culture doesn't significantly influence to motivation; and have significant to motivation indirectly through satisfaction work; 3) income out of salary significantly influence to motivation either directly or indirectly; 4) job satisfaction significantly influence to the motivation; 5) leadership significantly influence to job satisfaction; 6) organization culture significantly influence to the job satisfaction; and 7) income out of salary significantly influence to job satisfaction. Suggestion for this research are: 1) to headmaster of meteorological agency of Central Java must implemented the leadership style and forming the organization culture which oriented on job motivation; not only oriented on job satisfaction; and 2) to the next researcher must doing the research using qualitative about the leadership, organization culture, job satisfaction factors, and motivation factors of employees in Meteorological Agency of Central Java.
\end{abstract}

Keywords: leadership, organization culture, income out of salary, job satisfaction, and motivation.

Organisasi perlu memastikan kepuasan kerja para pegawainya secara berkesinambungan. Hal tersebut diperlukan organisasi tersebut untuk meraih sukses-sukses dan pencapaian-pencapai- an atas apa yang dicita-citakan. Kepuasan kerja dapat diartikan sebagai reaksi individu atas hal-hal yang dialami selama menjalani pekerjaan (Berry, 1997: 83). Dengan kata lain aktivitas 
kerja merupakan stimulus dan reaksi perasaan dari masing-masing individu para pegawai adalah respon. Dengan stimulus yang sama yaitu jenis pekerjaan yang sama, bekerja dalam kantor yang sama, mendapatkan gaji yang sama; tentu tidak mengakibatkan respon yang sama bagi masing-masing pegawai. Oleh karena itu kepuasan kerja dinyatakan sebagai "reaksi individu", karena kepuasan kerja (dan ketidakpuasannya) terdapat dalam diri masing-masing pegawai.

Seperti halnya kepemimpinan di dinas-dinas pemerintah lainnya, kepemimpinan di Balai Metrologi Jawa Tengah lebih bersifat defensif, yaitu melaksanakan aktivitas organisasi sesuai dengan petunjuk pelaksanaan dan teknis yang telah digariskan dan sedapat mungkin tidak berimprovisasi karena dapat menimbulkan permasalahan atau dianggap sebagai pelanggaran. Sikap kepemimpinan bersifat demokratis dan lunak. Bahkan beberapa yang pernah terjadi adalah kepemimpinan yang bersifat laissez faire. Diperlukan kepemimpinan yang inovatif dengan mampu membaca perubahan situasi dan kondisi dengan cepat. Disamping itu, diperlukan kepemimpinan yang mampu memberikan maklumat ataupun perintah yang secara cepat diterjemahkan oleh para pegawainya.

Kepemimpinan juga berhubungan dengan kepuasan kerja sebagaimana diungkapkan oleh Yukl (dalam Gopal dan Chowdhury, 2014: 5): "Employees are more satisfied with leaders who are considerate or supportive than with those who are either indifferent or critical towards subordinates". Pernyataan tersebut dapat dijelaskan bahwa pegawai akan lebih puas dengan pemimpin yang perhatian ataupun penuh dukungan dan pegawai tidak puas pada pemimpin yang acuh tak acuh ataupun terlalu kritis terhadap mereka.
Organisasi yang memiliki budaya organisasi yang tertanam kuat, dapat dipastikan beranggotakan para individu yang bermotivasi dan berkomitmen tinggi. Anggota-anggota ini akan rela mengorbankan diri demi tercapainya tujuan organisasi. Sementara itu, budaya organisasi yang lemah tidak mampu membuat pegawai mengidentifikasi dirinya dengan tujuan organisasi dan bekerja bersama-sama untuk mencapai tujuan tersebut (Tan, 2002: 97). Budaya organisasi bekaitan dengan bagaimana karyawan mempersiapkan karakteristik dari suatu budaya organisasi bukan dengan apakah para karyawan menyukai budaya atau tidak. Budaya organisasi adalah apa yang dipersiapkan karyawan dan cara persepsi itu menciptakan suatu pola keyakinan, nilai dan ekspektasi.

Faktor yang lain yang dapat mempengaruhi motivasi adalah penghasilan baik yang bersifat gaji ataupun penghasilan di luar gaji sesuai dengan teori-teori motivasi klasik. Motivasi berkaitan erat dengan kepuasan kerja. Kepuasan kerja menurut Indrawijaya (2000: 73) antara lain dapat dicapai melalui pekerjaan yang sesuai dengan bakat dan keahlian, pekerjaan yang untuk pelaksanaannya disediakan perlengkapan yang cukup, dan pekerjaan yang menyediakan informasi yang cukup lengkap mengenai tata cara pelaksanaannya.

\section{METODE PENELITIAN}

Penelitian dilakukan di Balai Metrologi Jawa Tengah dikarenakan merupakan instansi pemerintah yang dianggap berperan sentral dalam penjaminan kelayakan alat ukur takar dan timbang yang beredar dan digunakan di dalam aktivitas perekonomian masyarakat luas di wilayah Jawa Tengah. Penelitian menggunakan pendekatan kuantitatif. 
Populasi dalam penelitian ini adalah pegawai pada Balai Metrologi Jawa Tengah yang terdiri atas 6 balai metrologi wilayah, yaitu Tegal, Banyumas, Surakarta, Magelang, Semarang, dan Pati. Jumlah pegawai sebagai populasi penelitian adalah 160 orang. Sampel diambil secara acak dan proporsional dengan besar sampel ditentukan dengan rumus Slovin. Data primer diambil dengan kuesioner dan data-data sekunder diambil dengan menggunakan teknik wawancara dan observasi tidak terstruktur.

Variabel penelitian adalah Kepemimpinan $\left(\mathrm{X}_{1}\right)$ dijabarkan dari teori Hersey dan Blanchard (1995) dengan 16 butir kuesioner; Budaya Organisasi $\left(\mathrm{X}_{2}\right)$ dijabarkan dari teori Robbins (2008) dengan 18 butir kuesioner; Pendapatan di Luar Gaji $\left(\mathrm{X}_{3}\right)$; Kepuasan Kerja $\left(\mathrm{Y}_{1}\right)$ dijabarkan dari teori Kreitner dan Kinicki (2001) dengan 10 butir kuesioner; dan Motivasi $\left(\mathrm{Y}_{2}\right)$ dijabarkan dari teori Herzberg (1959) dengan 11 butir kuesioner. Adapun desain pengukuran kuesioner yang digunakan adalah dengan menggunakan 5 skala Likert's kecuali variabel Pendapatan di Luar Gaji $\left(\mathrm{X}_{3}\right)$ menggunakan pertanyaan terbuka. Kuesioner dinyatakan valid dan reliabel berdasarkan pengujian.

Sebelum dilakukan analisis data dengan regresi dan path analisis terlebih dahulu dilakukan uji asumsi dasar dan uji asumsi klasik regresi yaitu meliputi uji normalitas, uji multikolinearitas dan uji oto korelasi. Analisis data yang digunakan adalah analisis jalur dengan terlebih dahulu melakukan korelasi bivariat untuk mengetahui adanya korelasi antar variabel penelitian dan melakukan analisis regresi linear berganda untuk memperoleh nilai-nilai koefisien beta guna digunakan dalam analisis jalur. Karena variabel-variabel penelitian hendak diukur dengan angket maka digunakan validitas konstruksi yang dijabarkan dengan cara membangun teori atas variabel-variabel yang diteliti dan menjabarkan menjadi dimensi-dimensi variabel dan indikatorindikatornya. Selain uji validitas juga dilakukan uji reliabilitas dimana suatu instrumen dikatakan reliabel apabila instrumen tersebut dapat digunakan lebih dari satu kali dalam waktu yang berbeda namun tetap menunjukkan hasil yang relatif konsisten.

\section{HASIL}

Mayoritas responden penelitian berumur antara 41 - 50 tahun, yaitu sebanyak 45 orang $(39,47 \%)$; berjenis kelamin laki-laki, yaitu sebanyak 99 orang $(86,84 \%)$; dan berpendidikan S1 yaitu sebanyak 61 orang $(53,51 \%)$. Adapun berdasarkan wilayah kerja, responden penelitian berada dalam jumlah yang relatif sebanding karena telah ditetapkan proporsional.

Hasil analisis deskriptif persentase menjelaskan bahwa skor responden untuk variabel Kepemimpinan $\left(\mathrm{X}_{1}\right)$ adalah: 1$)$ skor terendah adalah 43 ; 2) skor tertinggi adalah 73 ; 3) rata-rata skor adalah 63.75. Dengan nilai rata-rata skor 63.75, dapat dinyatakan tingkat kepemimpinan di Balai Metrologi Wilayah Tegal adalah tinggi.

Hasil analisis deskriptif persentase menjelaskan bahwa skor responden untuk variabel Budaya Organisasi $\left(\mathrm{X}_{2}\right)$ adalah: 1) skor terendah adalah $61 ; 2$ ) skor tertinggi adalah $86 ; 3$ ) rata-rata skor adalah 75.74. Dengan nilai rata-rata skor 75.74 , dapat dinyatakan tingkat budaya organisasi di Balai Metrologi Wilayah Tegal adalah tinggi.

Hasil analisis deskriptif persentase menjelaskan bahwa skor responden untuk variabel Pendapatan di Luar Gaji $\left(\mathrm{X}_{3}\right)$ adalah: 1) skor terendah adalah $3.000 .000 ; 2)$ skor tertinggi adalah $10.000 .000 ; 3)$ rata-rata skor 
adalah 5.244.736,84. Dengan nilai ratarata skor 5.244.736,84, dapat dinyatakan tingkat pendapatan di luar gaji di Balai Metrologi Wilayah Tegal adalah rendah.

Hasil analisis deskriptif persentase menjelaskan bahwa skor responden untuk variabel Kepuasan Kerja ( $\mathrm{Y}_{1}$ ) adalah: 1) skor terendah adalah 26; 2) skor tertinggi adalah $48 ; 3$ ) rata-rata skor adalah 41,52. Dengan nilai rata-rata skor 41,52, dapat dinyatakan tingkat kepuasan kerja pegawai di Balai Metrologi Wilayah Tegal adalah tinggi.

Hasil analisis deskriptif persentase menjelaskan bahwa skor responden untuk variabel Motivasi $\left(\mathrm{Y}_{2}\right)$ adalah: 1) skor terendah adalah $41 ; 2$ ) skor tertinggi adalah $54 ; 3$ ) rata-rata skor adalah 48,11. Dengan nilai rata-rata skor 48,11 , dapat dinyatakan tingkat motivasi kerja pegawai di Balai Metrologi Wilayah Tegal adalah tinggi.

Analisis data dengan korelasi Bivariate Pearson, Regresi Linear Berganda, dan Analisis Jalur dilakukan dengan 2 tahap. Tahap pertama yaitu sub-struktural-1 melakukan analisis dengan variabel Kepemimpinan $\left(\mathrm{X}_{1}\right)$, Budaya Organisasi $\left(\mathrm{X}_{2}\right)$, dan Pendapatan di Luar Gaji $\left(\mathrm{X}_{3}\right)$ sebagai variabel eksogen sedangkan variabel Kepuasan Kerja $\left(\mathrm{Y}_{1}\right)$ sebagai variabel endogen. Tahap kedua yaitu sub-struktural-2 melakukan analisis dengan variabel Kepemimpinan $\left(\mathrm{X}_{1}\right)$, Budaya Organisasi $\left(\mathrm{X}_{2}\right)$, Pendapatan di Luar Gaji $\left(\mathrm{X}_{3}\right)$, dan Kepuasan Kerja $\left(\mathrm{Y}_{1}\right)$ sebagai variabel eksogen, sedangkan variabel Motivasi $\left(\mathrm{Y}_{2}\right)$ sebagai variabel endogen.

\section{PEMBAHASAN}

1. Kepemimpinan terhadap Kepuasan Kerja Pegawai Balai Metrologi Jawa Tengah

Dari hasil analisis data yang dilakukan dapat disimpulkan bahwa
Hasil analisis sub struktural-1 dengan analisis Bivariate Pearson menunjukkan adanya korelasi antar variabel-variabel eksogen dan antara variabel-variabel eksogen dengan variabel endogen. Analisis Regresi Linear Berganda memperoleh nilai $\mathrm{R}$ 0,615 , nilai $\mathrm{RSquare} 0,378$, nilai-nilai beta ketiga variabel eksogen adalah masing-masing $0,214,0,242$, dan 0,391 dengan nilai-nilai Sig. $<0,05$. Dengan demikian Kepemimpinan $\left(\mathrm{X}_{1}\right)$, Budaya Organisasi $\left(\mathrm{X}_{2}\right)$, dan Pendapatan di Luar Gaji $\left(\mathrm{X}_{3}\right)$ berpengaruh signifikan terhadap Kepuasan Kerja $\left(\mathrm{Y}_{1}\right)$.

Hasil analisis sub struktural-2 dengan analisis Bivariate Pearson menunjukkan adanya korelasi antar variabel-variabel eksogen dan antara variabel-variabel eksogen dengan variabel endogen. Analisis Regresi Linear Berganda memperoleh nilai $\mathrm{R}$ 0,621 , nilai RSquare 0,385 , nilai-nilai beta keempat variabel eksogen adalah: 1) Kepemimpinan $\left(\mathrm{X}_{1}\right)$ 0,061 dengan nilai Sig. 0,469 > 0,05 (tidak signifikan), 2) Budaya Organisasi $\left(\mathrm{X}_{2}\right)$ 0,076 dengan nilai Sig. 0,372 $>0,05$ (tidak signifikan), 3) Pendapatan di Luar Gaji $\left(X_{3}\right) 0,431$ dengan nilai Sig. $0,000<0,05$ (signifikan), dan 4) Kepuasan Kerja ( $\left.\mathrm{Y}_{1}\right)$ 0,029 dengan nilai Sig. 0,029<0,05 (signifikan).

Dengan demikian Kepemimpinan $\left(\mathrm{X}_{1}\right)$ dan Budaya Organisasi $\left(\mathrm{X}_{2}\right)$ tidak miliki pengaruh terhadap Motivasi $\left(\mathrm{Y}_{2}\right)$. Adapun Pendapatan di Luar Gaji $\left(\mathrm{X}_{3}\right)$ dan Kepuasan Kerja $\left(\mathrm{Y}_{1}\right)$ berpengaruh signifikan terhadap Motivasi $\left(\mathrm{Y}_{2}\right)$.

terdapat pengaruh positif signifikan Kepemimpinan $\left(\mathrm{X}_{1}\right)$ terhadap Kepuasan Kerja $\left(\mathrm{Y}_{1}\right)$. Semakin meningkat kepemimpinan maka semakin meningkat pula kepuasan kerja pegawai Balai Metrologi Jawa Tengah. Hal tersebut dibuktikan dengan nilai koefisien (beta) sebesar 0.214 atau dapat dinyatakan bahwa 
kontribusi pengaruh Kepemimpinan $\left(\mathrm{X}_{1}\right)$ terhadap Kepuasan Kerja $\left(\mathrm{Y}_{1}\right)$ adalah sebesar $0.214^{2}=0.046$ atau $4.6 \%$. Hipotesis alternatif "Terdapat pengaruh positif signifikan Kepemimpinan $\left(\mathrm{X}_{1}\right)$ terhadap Kepuasan Kerja ( $\left.\mathrm{Y}_{1}\right)$ " dapat diterima dibuktikan dengan nilai Sig. hitung sebesar 0,001< dari 0,005.

Kesimpulan tersebut mendukung hasil penelitian Ginanjar (2010) dengan judul "Pengaruh Kepemimpinan Terhadap Kepuasan Kerja Karyawan Pada Hotel Panghegar Bandung" dan juga penelitian Baihaqi (2010) dengan judul "Pengaruh Gaya Kepemimpinan Terhadap Kepuasan Kerja Dan Kinerja Dengan Komitmen Organisasi Sebagai Variabel Intervening (Studi Pada PT. Yudhistira Ghalia Indonesia Area Yogyakarta)". Kedua penelitian tersebut memberikan kesimpulan bawa kondisi, gaya, dan kualitas kepemimpinan dalam organisasi berpengaruh positif dan signifikan terhadap kepuasan kerja para karyawan.

2. Budaya Organisasi terhadap Kepuasan Kerja Pegawai Balai Metrologi Jawa Tengah

Dari hasil analisis data yang dilakukan dapat disimpulkan bahwa terdapat pengaruh positif signifikan Budaya Organisasi $\left(\mathrm{X}_{2}\right)$ terhadap Kepuasan Kerja $\left(\mathrm{Y}_{1}\right)$. Semakin meningkat kualitas budaya organisasi maka semakin meningkat pula kepuasan kerja pegawai Balai Metrologi Jawa Tengah. Hal tersebut dibuktikan dengan nilai koefisien (beta) sebesar 0.242 atau dapat dinyatakan bahwa kontribusi pengaruh Kepemimpinan $\left(\mathrm{X}_{1}\right)$ terhadap Kepuasan Kerja $\left(\mathrm{Y}_{1}\right)$ adalah sebesar $0.242^{2}=0.059$ atau 5.9\%. Hipotesis alternatif "Terdapat pengaruh positif signifikan Budaya Organisasi $\left(\mathrm{X}_{2}\right)$ terhadap Kepuasan Kerja ( $\mathrm{Y}_{1}$ )" dapat diterima dibuktikan dengan nilai Sig. hitung sebesar 0,009< dari 0,005 .
Kesimpulan tersebut mendukung hasil penelitian Swastika (2012) dengan judul "Pengaruh Budaya Organisasi terhadap Kepuasan Kerja Karyawan dan Dampaknya pada Kinerja Karyawan pada PT. Kusuma Dipa Nugraha" dan juga hasil penelitian Koesmono (2005) dengan judul "Pengaruh Budaya Organisasi Terhadap Motivasi dan Kepuasan Kerja Serta Kinerja Karyawan Pada Sub Sektor Industri Pengolahan Kayu Skala Menengah di Jawa Timur". Kedua penelitian tersebut memberikan kesimpulan bawa kondisi, karakter, dan kualitas budaya organisasi dalam organisasi berpengaruh positif dan signifikan terhadap kepuasan kerja para karyawan.

3. Pendapatan di Luar Gaji terhadap Kepuasan Kerja Pegawai Balai Metrologi Jawa Tengah

Dari hasil analisis data yang dilakukan dapat disimpulkan bahwa terdapat pengaruh positif signifikan Pendapatan di Luar Gaji $\left(\mathrm{X}_{3}\right)$ terhadap Kepuasan Kerja $\left(\mathrm{Y}_{1}\right)$. Semakin meningkat kuantitas pendapatan di luar gaji yang diperoleh oleh pegawai maka semakin meningkat pula kepuasan kerja pegawai Balai Metrologi Jawa Tengah. Hal tersebut dibuktikan dengan nilai koefisien (beta) sebesar 0.391 atau dapat dinyatakan bahwa kontribusi pengaruh Kepemimpinan $\left(\mathrm{X}_{1}\right)$ terhadap Kepuasan Kerja $\left(\mathrm{Y}_{1}\right)$ adalah sebesar $0.0 .391^{2}=$ 0.153 atau $15.3 \%$. Hipotesis alternatif "Terdapat pengaruh positif signifikan Pendapatan di Luar Gaji $\left(\mathrm{X}_{3}\right)$ terhadap Kepuasan Kerja ( $\left.\mathrm{Y}_{1}\right)$ " dapat diterima dibuktikan dengan nilai Sig. hitung sebesar $0,000<$ dari 0,005 .

Kesimpulan tersebut mendukung hasil penelitian Kulyana (2010) dengan judul "Pengaruh Insentif terhadap Kepuasan Kerja Karyawan pada PT. Tri Bakti Sarimas Pekanbaru" dan juga hasil penelitian Rahman (2013) dengan judul "Pengaruh Insentif terhadap Kepuasan 
Kerja Karyawan di PT Sinkona Indonesia Lestari (SIL) Ciater Subang". Kedua penelitian tersebut memberikan kesimpulan bawa besar insentif sebagai penghasilan di luar gaji yang diberikan oleh perusahaan kepada para karyawan berpengaruh positif dan signifikan terhadap kepuasan kerja para karyawan.

4. Kepemimpinan terhadap Motivasi Kerja Pegawai Balai Metrologi Jawa Tengah

Dari hasil analisis data yang dilakukan dapat disimpulkan bahwa tidak terdapat pengaruh Kepemimpinan $\left(\mathrm{X}_{1}\right)$ terhadap Motivasi $\left(\mathrm{Y}_{2}\right)$. Semakin meningkat kualitas kepemempinan maka semakin meningkat pula motivasi kerja pegawai Balai Metrologi Jawa Tengah walaupun tidak pada taraf yang signifikan. Hal tersebut dibuktikan dengan nilai koefisien (beta) sebesar 0.061 atau dapat dinyatakan bahwa kontribusi pengaruh Kepemimpinan $\left(\mathrm{X}_{1}\right)$ terhadap Kepuasan Kerja $\left(\mathrm{Y}_{1}\right)$ adalah sebesar $0.061^{2}=0.004$ atau $4 \%$. Hipotesis nihil "Tidak terdapat pengaruh Kepemimpinan $\left(\mathrm{X}_{1}\right)$ terhadap Motivasi $\left(\mathrm{Y}_{2}\right)$ " dinyatakan diterima dibuktikan dengan nilai Sig. hitung sebesar 0,469> dari 0,005 .

Namun demikian, Kepemimpinan $\left(\mathrm{X}_{1}\right)$ mendapatkan penguatan dalam pengaruhnya terhadap Motivasi $\left(\mathrm{Y}_{2}\right)$ jika dimediasi oleh Kepuasan Kerja $\left(\mathrm{Y}_{1}\right)$ berdasarkan hasil hitung $\rho \mathrm{y}_{2} \mathrm{x}_{1}+\left(\rho \mathrm{y}_{1} \mathrm{x}_{1} \mathrm{x}\right.$ $\left.\rho \mathrm{y}_{2} \mathrm{y}_{1}\right)=0,061+(0.214 \times 0,211)=$ 0,106 . Dengan demikian dapat disimpulkan bahwa tingkat kualitas kepemimpinan akan mendapatkan penguatan dalam pengaruhnya terhadap motivasi kerja pegawai Balai Metrologi Jawa Tengah jika terdapat kepuasan kerja pada para pegawai.

Kesimpulan tersebut tidak mendukung hasil penelitian Reni (2015) yang berjudul "Pengaruh Kepemimpinan terhadap Motivasi Kerja Karyawan pada
UD. Surya Phone di Samarinda". Kesimpulan tersebut juga tidak mendukung hasil penelitian Gustian (2015) yang berjudul "Pengaruh Kepemimpinan Terhadap Motivasi Kerja Pegawai Pada Univesitas Negeri Padang". Kedua penelitian tersebut menyatakan bahwa aspek kepemimpinan dalam organisasi berpengaruh positif dan signifikan terhadap kepuasan kerja para pegawai dan karyawan.

Hal ini terjadi disebabkan gaya kepemimpinan yang diterapkan oleh para pemimpin di Balai Metrologi Jawa Tengah lebih bersifat memberikan kepuasan dalam bekerja dibandingkan dengan memcu semangat bekerja para pegawai di Balai Metrologi Jawa Tengah. Berdasarkan pengamatan (di luar pengukuran kuesioner), gaya kepemimpinan yang diterapkan oleh para pemimpin di Balai Metrologi Jawa Tengah lebih bersifat paternalistik. Kondisi kepemimpinan semacam ini memang menimbulkan rasa hormat, rasa akrab, dan rasa nyaman bagi segenap pegawai Balai Metrologi Jawa Tengah. Namun demikian kurang mampu memberikan kontribusi dalam hal merangsang timbulnya motivasi kerja yang tinggi bagi segenap pegawai Balai Metrologi Jawa Tengah.

5. Budaya Organisasi terhadap Motivasi Kerja Pegawai Balai Metrologi Jawa Tengah

Dari hasil analisis data yang dilakukan dapat disimpulkan bahwa tidak terdapat pengaruh Budaya Organisasi $\left(\mathrm{X}_{2}\right)$ terhadap Motivasi $\left(\mathrm{Y}_{2}\right)$. Semakin meningkat kualitas kondisi budaya organisasi maka semakin meningkat pula motivasi pegawai Balai Metrologi Jawa Tengah walaupun tidak pada taraf yang signifikan. Hal tersebut dibuktikan dengan nilai koefisien (beta) sebesar 0.076 atau dapat dinyatakan bahwa kontribusi pengaruh Budaya 
Organisasi $\left(\mathrm{X}_{2}\right)$ terhadap Motivasi $\left(\mathrm{Y}_{2}\right)$ adalah sebesar $0.076^{2}=0.006$ atau $6 \%$. Hipotesis nihil "Tidak terdapat pengaruh Budaya Organisasi $\left(\mathrm{X}_{2}\right)$ terhadap Motivasi $\left(\mathrm{Y}_{2}\right)$ " dinyatakan diterima dibuktikan dengan nilai Sig. hitung sebesar 0,372 > dari 0,005.

Namun demikian, Budaya Organisasi $\left(\mathrm{X}_{2}\right)$ mendapatkan penguatan dalam pengaruhnya terhadap Motivasi $\left(\mathrm{Y}_{2}\right)$ jika dimediasi oleh Kepuasan Kerja $\left(\mathrm{Y}_{1}\right)$ berdasarkan hasil hitung $\rho_{2} \mathrm{x}_{2}+$ $\left(\rho y_{1} x_{2} \times \rho_{2} y_{1}\right)=0,076+(0.2420,211)=$ 0,127 . Dengan demikian dapat disimpulkan bahwa tingkat kualitas dan kondisi budaya organisasi akan mendapatkan penguatan dalam pengaruhnya terhadap motivasi kerja pegawai Balai Metrologi Jawa Tengah jika terdapat kepuasan kerja pada para pegawai.

Kesimpulan ini tidak mendukung hasil penelitian Koesmono (2005) yang berjudul "Pengaruh Budaya Organisasi Terhadap Motivasi Dan Kepuasan Kerja Serta Kinerja Karyawan pada Sub Sektor Industri Pengolahan Kayu Skala Menengah Di Jawa Timur" dan tidak mendukung hasil penelitian Rahayu (2013) yang berjudul "Pengaruh Budaya Organisasi terhadap Motivasi Kerja Pegawai di Balai Pelatihan Pendidik dan Tenaga Pendidikan Kejuruan (BPPTKPK) Dinas Pendidikan Provinsi Jawa Barat.

Hal tersebut terjadi karena berdasarkan observasi (di luar data kuesioner) diketahui bahwa budaya organisasi di Balai Metrologi Jawa Tengah lebih bersifat kekeluargaan dan kurang bersifat kompetitif. Sebenarnya hal tersebut dapat diperbaiki dengan hadirnya tipe pemimpin yang bersifat $j o b$ oriented bukan pemimpin paternalistik yang bersifat human oriented. Dengan demikian, kepemimpinan yang lebih bersifat paternalistik turut membentuk budaya organisasi yang nyaman penuh dengan rasa kekeluargaan; namun di sisi lain para pegawai menjadi kurang agresif dan kurang memiliki semangat kompetisi. Sisi positifnya adalah para pemimpin di Balai Metrologi Jawa Tengah tidak perlu berlaku direktif kepada para bawahannya, para staf sudah bekerja dengan baik dan berusaha memenuhi tanggung jawab yang telah dibebankan.

6. Pendapatan di Luar Gaji terhadap Motivasi Kerja Pegawai Balai Metrologi Jawa Tengah

Dari hasil analisis data yang dilakukan dapat disimpulkan bahwa terdapat pengaruh positif signifikan Pendapatan di Luar Gaji $\left(\mathrm{X}_{3}\right)$ terhadap Motivasi Kerja $\left(\mathrm{Y}_{2}\right)$. Semakin meningkat nilai pendapatan di luar gaji yang diperoleh maka semakin meningkat pula motivasi kerja pegawai Balai Metrologi Jawa Tengah. Hal tersebut dibuktikan dengan nilai koefisien (beta) sebesar 0.431 atau dapat dinyatakan bahwa kontribusi pengaruh Pendapatan di Luar Gaji $\left(\mathrm{X}_{3}\right)$ terhadap Motivasi Kerja $\left(\mathrm{Y}_{2}\right)$ adalah sebesar $0.431^{2}=0.1858$ atau $18,58 \%$. Hipotesis alternatif "Terdapat pengaruh positif signifikan Pendapatan di Luar Gaji $\left(\mathrm{X}_{3}\right)$ terhadap Motivasi Kerja $\left(\mathrm{Y}_{2}\right)$ " dapat diterima dibuktikan dengan nilai Sig. hitung sebesar $0,000<$ dari 0,005.

Kesimpulan tersebut mendukung hasil penelitian Alfadito (2013) dengan judul "Pengaruh Pemberian Insentif terhadap Peningkatan Motivasi Kerja Karyawan Bagian SDM di PT Kahatex" dan juga penelitian Indrayuda (2012) dengan judul "Pengaruh Pemberian Insentif terhadap Motivasi Kerja Karyawan di Hotel Gurame Bandung”. Kedua penelitian tersebut memberikan kesimpulan bawa pendapatan di luar gaji berupa insentif berpengaruh positif dan signifikan terhadap kepuasan kerja para karyawan. 


\section{Kepuasan Kerja terhadap Motivasi Kerja}

Dari hasil analisis data yang dilakukan dapat disimpulkan bahwa terdapat pengaruh positif signifikan Kepuasan Kerja ( $\left.\mathrm{Y}_{1}\right)$ terhadap Motivasi Kerja $\left(\mathrm{Y}_{2}\right)$. Semakin tinggi tingkat kepuasan pegawai atas kinerja mereka maka semakin tinggi pula motivasi kerja pegawai Balai Metrologi Jawa Tengah. Hal tersebut dibuktikan dengan nilai koefisien (beta) sebesar 0.211 atau dapat dinyatakan bahwa kontribusi pengaruh Kepuasan Kerja $\left(\mathrm{Y}_{1}\right)$ terhadap Motivasi $\operatorname{Kerja}\left(\mathrm{Y}_{2}\right)$ adalah sebesar $0.211^{2}=$ 0.0445 atau $4,45 \%$. Hipotesis alternatif "Terdapat pengaruh positif signifikan Kepuasan Kerja ( $\left.\mathrm{Y}_{1}\right)$ terhadap Motivasi Kerja $\left(\mathrm{Y}_{2}\right)$ " dapat diterima dibuktikan dengan nilai Sig. hitung sebesar 0,029< dari 0,005 .

Kesimpulan tersebut mendukung hasil penelitian Alfadito (2013) dengan judul "Pengaruh Pemberian Insentif terhadap Peningkatan Motivasi Kerja Karyawan Bagian SDM di PT Kahatex" dan juga penelitian Indrayuda (2012) dengan judul "Pengaruh Pemberian Insentif terhadap Motivasi Kerja Karyawan di Hotel Gurame Bandung”. Kedua penelitian tersebut memberikan kesimpulan bawa pendapatan di luar gaji berupa insentif berpengaruh positif dan signifikan terhadap kepuasan kerja para karyawan.

\section{PENUTUP}

Berdasarkan hasil penelitian yang telah dilakukan di Balai Metrologi Jawa Tengah dapat disimpulkan bahwa:

1. Kepemimpinan berpengaruh signifikan terhadap kepuasan kerja pegawai Balai Metrologi Jawa Tengah.

2. Budaya organisasi berpengaruh signifikan terhadap kepuasan kerja pegawai Balai Metrologi Jawa Tengah.

3. Pendapatan di luar gaji berpengaruh signifikan terhadap kepuasan kerja pegawai Balai Metrologi Jawa Tengah.

4. Kepemimpinan berpengaruh tidak signifikan secara langsung terhadap motivasi pegawai Balai Metrologi Jawa Tengah; dan kepemimpinan berpengaruh signifikan terhadap motivasi secara tidak langsung melalui kepuasan kerja pegawai Balai Metrologi Jawa Tengah.

5. Budaya organisasi berpengaruh tidak signifikan secara langsung terhadap motivasi pegawai Balai Metrologi Jawa Tengah; dan budaya organisasi berpengaruh signifikan secara tidak langsung terhadap motivasi melalui kepuasan kerja pegawai Balai Metrologi Jawa Tengah.

6. Pendapatan di luar gaji berpengaruh signifikan terhadap motivasi baik secara langsung maupun secara tidak langsung melalui kepuasan kerja pegawai Balai Metrologi Jawa Tengah.

7. Kepuasan kerja berpengaruh signifikan terhadap motivasi pegawai Balai Metrologi Jawa Tengah.

Hasil penelitian menunjukkan bahwa pendapatan di luar gaji berpengaruh signifikan secara langsung maupun tidak langsung terhadap motivasi kerja pegawai Balai Metrologi Jawa Tengah. Oleh sebab itu, sistem pemberian pendapatan di luar gaji yang telah ada diharapkan dapat dipertahankan dan bila memungkinkan dapat ditingkatkan melalui penghargaan-penghargaan yang lain atas prestasi kerja yang diraih.

Selanjutnya, kepemimpinan dan budaya organisasi hanya berpengaruh signifikan terhadap motivasi kerja pegawai Balai Metrologi Jawa Tengah jika melalui kepuasan kerja pegawai 
Balai Metrologi Jawa Tengah. Maka dari itu perlu dilakukan penelitian secara komprehensif mengenai gaya kepemimpinan dan budaya organisasi yang dapat meningkatkan motivasi kerja pegawai Balai Metrologi Jawa Tengah.

Namun demikian, kepemimpinan dan budaya organisasi berpengaruh signifikan terhadap kepuasan kerja pegawai Balai Metrologi Jawa Tengah. Dengan kata lain diperlukan gaya-gaya kepemimpinan yang lebih inovatif dan budaya organisasi yang lebih kondusif di Balai Metrologi Jawa Tengah; yaitu gaya kepemimpinan dan budaya organisasi yang lebih memicu motivasi kerja para pegawai tidak hanya menimbulkan rasa kepuasan dalam bekerja.

Saran yang dapat diberikan kepada Kepala Balai Metrologi Jawa Tengah adalah melakukan upaya-upaya penerapan gaya-gaya kepemimpinan yang lebih berorientasi kerja kepada para bawahan langsung sehingga dapat diteruskan kepada para staff secara keseluruhan. Disamping itu, disarankan kepada Kepala Balai Metrologi Jawa
Tengah agar melakukan upaya-upaya dalam rangka pembentukan budaya organisasi yang lebih berorientasi pada motivasi kerja; tidak hanya berorientasi kepada kepuasan bekerja.

Bagi peneliti-peneliti selanjutnya, terutama bagi peneliti-peneliti yang hendak melakukan penelitian dengan metode dan variabel penelitian serupa disarankan agar melakukan kritik dan koreksi atas kelemahan-kelemahan yang terdapat pada penelitian ini. Adapun hasil penelitian ini dapat dijadikan bahan rujukan untuk melakukan penelitian dengan model, metode dan variabel penelitian yang serupa.

Selanjutnya disarankan kepada peneliti-peneliti selanjutnya untuk dapat mengungkap secara kualitatif mengenai gaya kepemimpinan dan budaya organisasi yang ada di Balai Metrologi Jawa Tengah. Demikian juga perlu diungkap secara kualitatif mengenai faktor-faktor kepuasan kerja dan faktor-faktor motivasi pada pegawai di Balai Metrologi Jawa Tengah.

\section{DAFTAR PUSTAKA}

Berry, L. M. 1998. Psychology at Work (2 ${ }^{\text {nd }}$ ed). New York: Mc. Graw Hill Company.

Hersey, Paul dan Blanchard, Ken. 1995. Manajemen Perilaku Organisasi, Pendayagunaan Sumber Daya Manusia. Jakarta: Penerbit Erlangga.

Gopal, R. dan Chowdhury, Rima Ghose. 2014. Leadership Styles and Employee Motivation: an Empirical Investigation in a Leading oil Company in India. IMPACT: International Journal of Research in Business Management (IMPACT: IJRBM) ISSN(E): 2321-886X; ISSN(P): 2347-4572 Vol. 2, Issue 5, May 2014, 1-10.

Indrawijaya, Adam Ibrahim. 2010. Teori, Perilaku, dan Budaya Organisasi. Bandung: Refika Aditama.

Kreitner, Robert dan Angelo Kinicki. 2005. Perilaku Organisasi, Buku 1, Edisi Kelima. Jakarta: Salemba Empat.

Robbins, Stephen P. 2008. Organizational Behaviour, Tenth Edition (Perilaku Organisasi Edisi ke Sepuluh) Alih Bahasa Drs. Benyamin Molan. Jakarta: Salemba Empat. 
MULTIPLIER - Vol. I No. 2 Mei 2017

Tan, Victor S. L. 2002. Changing Your Corporate Culture. Singapore: Time Books International. 